\title{
Hosting Capacity Assessment and Improvement for Photovoltaic-Based Distributed Generation in Distorted Distribution Networks
}

\author{
Selcuk Sakar, \\ Electrical and Electronics \\ Department, Gediz \\ University \\ Izmir, Turkey \\ selcuk.sakar@gediz.edu.tr
}

\author{
Murat E. Balci, \\ Electrical and Electronics \\ Department, Balikesir \\ University \\ Balikesir, Turkey \\ mbalci@balikesir.edu.tr
}

\author{
Shady H. E. Abdel Aleem, \\ 15th of May Higher \\ Institute of Engineering, \\ Cairo, Egypt \\ engyshady@ieee.org
}

\author{
Ahmed F. Zobaa \\ College of Engineering, \\ Design \& Physical Sciences, \\ Brunel University London, \\ Uxbridge, United Kingdom \\ azobaa@ieee.org
}

\begin{abstract}
In this paper, the hosting (or maximum allowable) capacity of a photovoltaic (PV)-based distributed generation (DG) unit for a typical two bus distorted distribution system, is analyzed. The harmonic constraints, total and individual harmonic distortion limits stated in IEEE Standard 519, and the conventional hosting capacity constraints, bus rms voltage limit and the current carrying capability limit of the supply cables are taken into account. In the analysis, various simulations are carried out to show the effect of the nonlinearity degrees of the loads on the system's hosting capacity. It is clearly seen from the analysis results that the harmonic distortion limits significantly constrain the PV-based DG unit hosting capacity for the higher nonlinearity levels of the consumer. Accordingly, a C-type filter is designed to maximize the hosting capability of the studied system while providing desired power factor and satisfying the harmonic and conventional hosting capacity constraints. Besides, the numerical results are given to point out that a higher allowable hosting capacity is obtained with the proposed filter design approach compared to two traditional filter design approaches, which aims to attain minimization of voltage total harmonic distortion and minimization of current total demand distortion by considering the same constraints of the proposed approach.
\end{abstract}

Keywords-Distributed generation; harmonic analysis; hosting capacity; optimization; passive filters; power quality.

\section{INTRODUCTION}

The distributed generation (DG) unit can be expressed as a small source of electric power, which is not a part of a large central power source, and it is placed close to the consumers or the load side of the distribution systems [1]-[3]. In the last decade, the DG units have widely been employed in the distribution systems since they have several benefits for the power networks such as improvement of the voltage profile, reduction of the line loss, enhancement of system reliability and security, increment of overall energy efficiency and reduction of the system cost.

Appropriate selection of their capacity is the main factor to increase the benefits gained from them. Inappropriate selection of the DG capacity can lead to undesirable effects such as higher losses and overvoltage in the system [4], [5].
Accordingly, optimal planning (sizing and sitting) of DG units in the distribution system is studied in many works [6], [7]. In these works, conventionally, minimization of the system losses, improvement of the voltage profile, enhancement of the system reliability, and maximization of the DG hosting capacity, were considered as the objectives of the optimal planning problem of DG units. It also has some constraints such as bus voltage, loading capability of the supply lines and the power capacity of DG units.

On the other hand, for today's power systems, one of the most important power quality problems is the harmonic voltage and current distortion. Since harmonic distortion causes excessive losses or heating of equipment as supply lines, transformers, power factor correction capacitors and induction motors; it decreases their lifetime [8]. In addition, the harmonic distortion leads to reduce the efficiency of the energy transfer, or power factor [9], [10]. To avoid these problems, the international standards such as IEEE Standard 519 imposes limits for individual and total harmonic distortion of PCC voltages and currents [11]. Accordingly, some recent studies investigated the impact of the harmonic limitations, given in the standards such as IEEE Standard 519 on the hosting capacity of the distribution systems for the DG units with inverter interfaces generating harmonic distortion [12]-[19]. In general, these studies concluded that the maximum allowable harmonic distortion levels stated in the standards considerably limit the hosting capacity of the systems for the DG units with inverter interfaces. Accordingly, [14] and [15] pointed out that passive harmonic filters should be employed for the improvement of the maximum allowable DG penetration level in the system.

In the first part of this paper, the PV-based DG hosting (or maximum allowable) capacity of a typical two-bus distorted distribution system is evaluated for various nonlinearity levels of the load side. For the evaluation, the hosting capacity is determined by considering the harmonic constraints, total and individual harmonic distortion limits stated in IEEE Standard 519 , and the conventional hosting capacity constraints, bus rms voltage limit and the current carrying capability limit of the supply cables. 
In the second part of this study, a C-type filter is employed to maximize the hosting capacity while satisfying the IEEE standard 519 voltage and current harmonic distortion limits, bus rms voltage and the line's current carrying capability limit, and providing the desired power factor. For the studied distorted distribution system, the proposed and the traditional passive filter design approaches are evaluated by regarding their impact on the hosting capacity.

\section{AN AlgORITHM TO DETERMINE PV-BASED DG UNIT HOSTING CAPACITY OF A TYPICAL INDUSTRIAL SYSTEM}

In this section, an algorithm is provided to determine the PV-based DG hosting capacity of the typical industrial power system given in Fig. 1. This system was considered as a benchmark system to test the performance of optimal passive filter designs in many papers [20]-[24]. In the system, there are a symmetric distribution line, a group of balanced linear and nonlinear loads, a PV-based DG unit with its own transformer and a C-type passive harmonic filter.

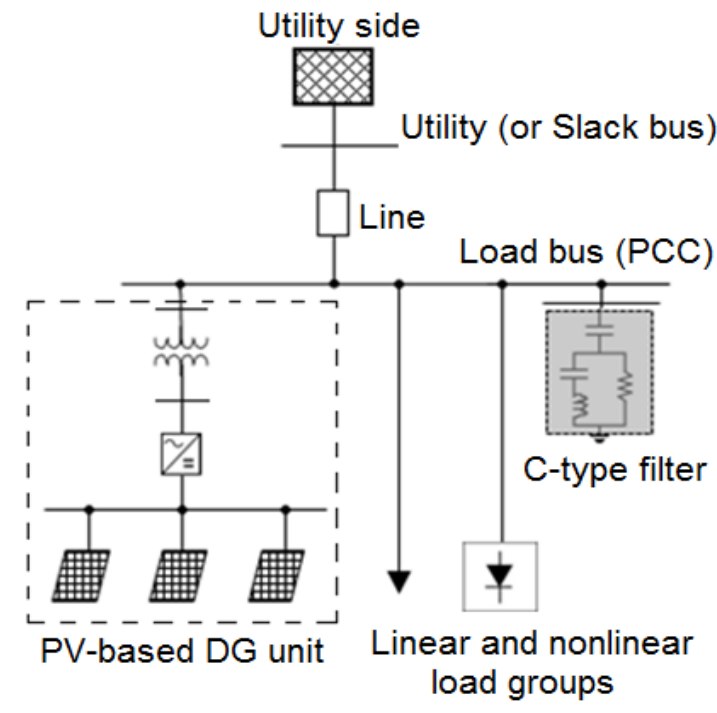

Fig. 1. Single- line diagram of the distribution system under study.

An algorithm is developed to determine the hosting capacity of the above-detailed system. Additionally, its flowchart is given in Fig. 2. In the algorithm, the active power $\left(\mathrm{P}_{\mathrm{PV}}\right)$ generated by the PV-based DG unit is iteratively increased, and the decoupled harmonic power flow (DHPF) of the system is employed to run for each $\mathrm{P}_{\mathrm{PV}}$ iterative value. Hence, the iteration loop continues without exceeding the operating limits given below:

1) Voltage limits: The rms value of the PCC voltage should be bounded by its lower (0.9 p.u.) and upper limit (1.1 p.u.);

$$
0.9 \leq V_{r m s}=\sqrt{\sum_{h \geq 1} V_{h}^{2}} \leq 1.1
$$

2) Individual harmonic distortion limits: According to IEEE 519, the $h$ th harmonic supply line current and PCC voltage distortions $\left(I_{h}\right.$ and $\left.V_{h}\right)$ should be confined as;

$$
I_{h} \leq \operatorname{MaxI}_{h}
$$

$$
V_{h} \leq \operatorname{Max}_{h}
$$

where $\operatorname{MaxI}_{h}$ and $\operatorname{MaxV}_{h}$ denote the maximum acceptable values of $I_{h}$ and $V_{h}$ in IEEE 519.

3) Total harmonic distortion limits: According to IEEE standard 519, the total demand distortion of the supply line current $(T D D I)$ and total harmonic distortion of the PCC voltage (THDV) should be limited as;

$$
\begin{aligned}
& T D D I=100 \frac{\sqrt{\sum_{h} I_{h}^{2}}}{I_{R}} \leq \operatorname{MaxTDDI} \\
& T H D V=100 \frac{\sqrt{\sum_{h} V_{h}^{2}}}{V_{1}} \leq \text { MaxTHDV }
\end{aligned}
$$

where MaxTDDI and MaxTHDV denote the maximum acceptable values of the TDDI, and THDV determined in the IEEE Standard, and $I_{R}$ is the rated line current.

4) Current carrying capability of the line: Under harmonically distorted line currents; the current carrying capability of the line, called as the harmonic derating factor $(H D F)$, should not exceed $100 \%$, so that;

$$
H D F=100 \sqrt{\left[1+\sum_{h \geq 2} \frac{R_{S h}}{R_{S 1}}\left(\frac{I_{h}}{I_{1}}\right)^{2}\right]} \leq 100
$$

where $R_{S 1}$ and $R_{S h}$ are the fundamental and $h$ th harmonic line cable resistances.

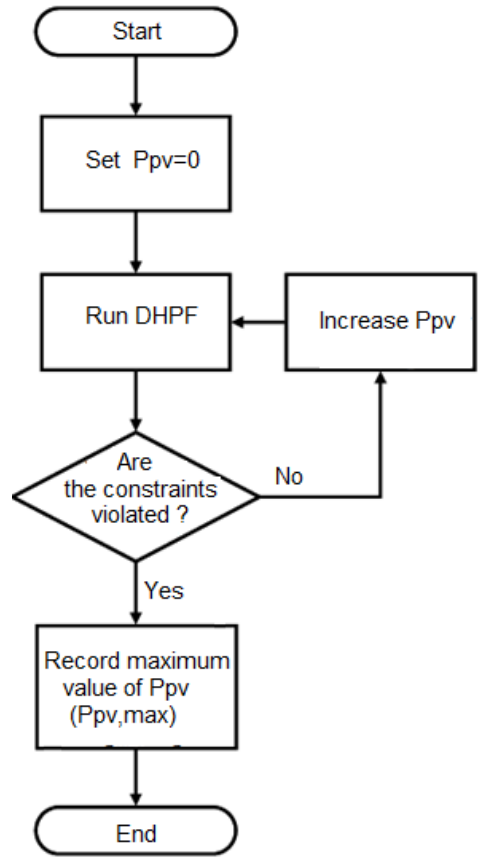

Fig. 2. The flowchart of the algorithm used for the determination of the hosting capacity of the studied system.

After determining $P_{\mathrm{PV} \text {,max }}$ value, which means the maximum allowable active power generation of the PV-based DG unit without exceeding the constraints given in (1)-(6), the 
hosting capacity (HC) of the system is calculated in terms of $P_{\mathrm{PV}, \text { max }}$ and the rated power of the DG bus $\left(S_{\text {rated }}\right)$, as follows:

$$
H C=\frac{P_{P V, \text { max }}}{S_{\text {rated }}} 100
$$

In the proposed algorithm, DHPF comprises three main steps: (i) power flow analysis at the fundamental frequency, (ii) the harmonic impedances of the linear loads and current harmonic components of the nonlinear loads and PV-based DG units are updated according to the results of the fundamental power flow and (iii) calculation of the non-fundamental harmonic bus voltages using the nodal equations at each harmonic order [13]:

$$
\left[Y_{h}\right]\left[V_{h}\right]=\left[I_{h}\right]
$$

Newton-Raphson algorithm, which is well-known in the literature, is used for the power flow analysis at the fundamental frequency [25].

For the calculation of the non-fundamental bus voltages, the interaction among the different harmonic orders of voltages/currents is assumed as negligible, and accordingly, the admittance matrix $\left[Y_{h}\right]$ is formulated individually for each harmonic order. The $h$ th harmonic admittance matrix should be constructed by considering the $h$ th harmonic admittances of the linear load $\left(\mathrm{Y}_{\mathrm{Lh}}\right)$, the supply line $\left(\mathrm{Y}_{\mathrm{Sh}}\right)$ and the C-type filter $\left(\mathrm{Y}_{\mathrm{Fh}}\right)$ that are given below.

$$
\begin{aligned}
Y_{L h} & =\frac{P_{L 1}}{V_{1}^{2}}-j \frac{Q_{L 1}}{V_{1}^{2}} \\
Y_{S h} & =\frac{1}{R_{S h}+j h X_{S}} \\
Y_{F h} & =\frac{1}{\left[-j \frac{X_{C F 1}}{h}+\frac{j R_{F} X_{F}\left(h^{2}-1\right)}{h^{2} R_{F}+j X_{F}\left(h^{2}-1\right)}\right]}
\end{aligned}
$$

where $V_{1}, P_{\mathrm{L} 1}, Q_{\mathrm{L} 1}, R_{\mathrm{Sh}}$ and $X_{\mathrm{S}}$ represent the PCC phase-toneutral voltage fundamental harmonic rms value, the singlephase fundamental harmonic active power of the linear load, the single-phase fundamental harmonic reactive power of the linear load, and the $h$ th harmonic resistance and fundamental harmonic inductive reactance of the supply line's single-phase, respectively. Here it should be noted that the fundamental harmonic voltage and power quantities are determined according to the results of the fundamental harmonic power flow analysis. In (11), $R_{\mathrm{F}}$ and $X_{\mathrm{CF} 1}$ are the resistance and the main capacitor's fundamental reactance of the C-type filter, of which single-phase equivalent circuit given in Fig. 3. Since that kind of filter should behave like a single capacitor $\left(\mathrm{X}_{\mathrm{CF} 1}\right)$ at the fundamental frequency, the fundamental harmonic reactances $\left(\mathrm{X}_{\mathrm{CF} 2}\right.$ and $\left.\mathrm{X}_{\mathrm{LF}}\right)$ of auxiliary capacitor and inductor have the same value denoted as $\mathrm{X}_{\mathrm{F}}$ in Equation (11).

On the other side, $\left[I_{h}\right]$ consists of the non-fundamental current harmonics of the non-linear load and PV-based DG unit, which are modelled as harmonic current source for nonfundamental harmonic orders, so that;

$$
\bar{I}_{C h}=C(h) \bar{I}_{C 1}
$$

where $\bar{I}_{C 1}$ is the phasor value of the fundamental harmonic current of the nonlinear devices (nonlinear load and PV-based DG unit), and $C(h)$ is the ratio between the $h$ th harmonic current and fundamental harmonic current of these devices. $C(h)$ is a predetermined value for each harmonic order, and $\bar{I}_{C 1}$ is found regarding the fundamental harmonic power flow results, which are $V_{l}$ and the nonlinear devices' fundamental harmonic power quantities as $P_{N l}$ and $Q_{N I}$.

$$
\bar{I}_{C 1}=\left[\frac{P_{N 1}+j Q_{N 1}}{V_{1}}\right]^{*}
$$

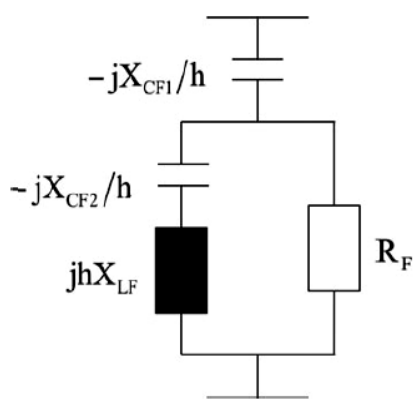

Fig. 3. Single- phase circuit of the C-type filter.

\section{ANALYSIS RESULTS OF THE PV HOSTING CAPACITY UNDER NONLINEAR LOADING CONDITONS}

In this section, for the studied industrial power distribution system without the C-type filter, the effect of the nonlinearity degree of loads on the system's hosting capacity is evaluated using the algorithm presented in Section II. For the simulation based analysis, the harmonic spectrum of the nonlinear load's (which is a six-pulse converter) current is predetermined as shown in Table I. In addition, for the analysis, the harmonic spectrum of a typical PV-based DG unit is considered as illustrated in Table II [26]. Regarding the IEEE Standard 1547 [27], it is also assumed that the PV-based DG unit generates only active power.

The simulation system has $13.8 \mathrm{kV}$ sinusoidal and balanced three-phase utility voltages, and the symmetric three-phase distribution line with voltage and current ratings are given as $13.8 \mathrm{kV}$ and $314 \mathrm{~A}$. For fundamental frequency, the resistance and inductive reactance of the distribution line are defined as $R_{\mathrm{S} 1}=0.855 \Omega$ and $X_{S}=1.165 \Omega$, respectively.

TABLE I. HARMONIC CURRENT SPECTRUM OF THE NONLINER LOAD.

\begin{tabular}{cc|cc}
\hline $\mathrm{h}$ & Magnitude (\%) & $\mathrm{h}$ & Magnitude (\%) \\
\hline 1 & 100 & 17 & 5.9 \\
5 & 20 & 19 & 5.3 \\
7 & 14.3 & 23 & 4.3 \\
11 & 9.1 & 25 & 4.0 \\
13 & 7.7 & 29 & 3.4 \\
\hline
\end{tabular}


TABLE II. HARMONIC CURRENT SPECTRUM OF THE PV-BASED DG UNIT.

\begin{tabular}{cc|cc|cc}
\hline $\mathrm{h}$ & $\begin{array}{c}\text { Magnitude } \\
(\%)\end{array}$ & $\mathrm{h}$ & $\begin{array}{c}\text { Magnitude } \\
(\%)\end{array}$ & $\mathrm{h}$ & $\begin{array}{c}\text { Magnitude } \\
(\%)\end{array}$ \\
\hline 1 & 100.00 & 11 & 0.6719 & 21 & 0.4987 \\
2 & 1.1294 & 12 & 0.7963 & 22 & 0.3980 \\
3 & 3.2708 & 13 & 0.4559 & 23 & 0.2093 \\
4 & 0.2624 & 14 & 1.0623 & 24 & 0.3538 \\
5 & 3.4828 & 15 & 0.3045 & 25 & 1.3338 \\
6 & 0.1244 & 16 & 0.5026 & 26 & 0.1925 \\
7 & 1.1229 & 17 & 1.4810 & 27 & 0.6109 \\
8 & 0.8193 & 18 & 0.5871 & 28 & 1.1996 \\
9 & 0.4866 & 19 & 1.1377 & 29 & 0.8976 \\
10 & 0.8423 & 20 & 0.7120 & 30 & 0.6741 \\
\hline
\end{tabular}

The load side's nonlinearity percentage (or the ratio of the apparent powers drawn by the nonlinear loads and total loads connected to the PCC) is gradually increased from 5\% to $30 \%$ to investigate the effects of the nonlinearity level of nonlinear loads on the hosting capacity. For all nonlinearity percentages, the apparent power of the total load is kept at its rated value as 7.5 MVA. Accordingly, for all simulated nonlinearity percentage ratios, the hosting capacity of the system is determined by using the developed algorithm, and the results are plotted in Fig. 4

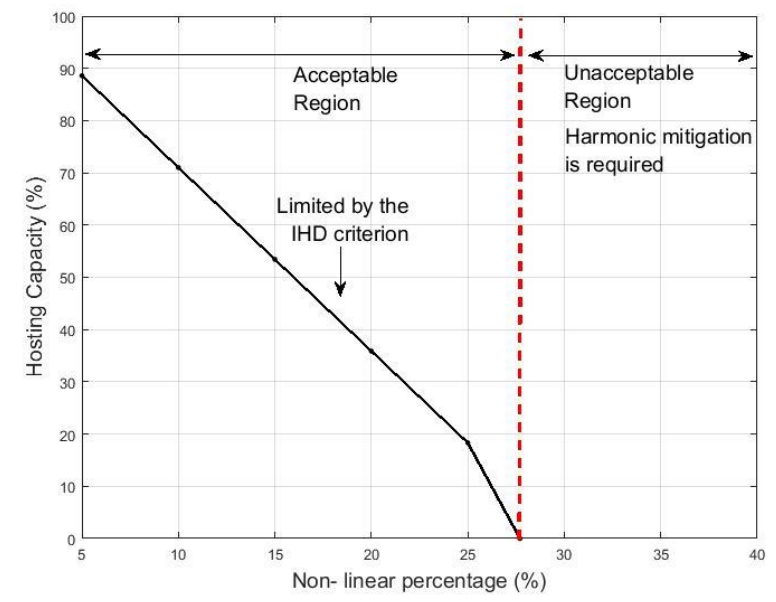

Fig. 4. The hosting capacity of the studied system for different nonlinearity percentages of the loads.

It can be seen from the figure that the hosting capacity dramatically decreases from $89 \%$ to $0 \%$ with the variation of the non-linearity percentage between $5 \%$ and $28 \%$. Thus, it can clearly be mentioned that a harmonic mitigation equipment such as the passive harmonic filter is required to improve the hosting capacity of the system under heavily nonlinear loading conditions.

\section{A SOLUTION TO IMPROVE THE HOSTING CAPACITY: PASSIVE FILTERS}

For the distorted systems, improvement of the PV-based DG hosting capacity can be achieved via installations of the passive harmonic filters [14], [15]. For this aim, optimal design of the C-type passive harmonic filter is formulated according to the proposed and traditional approaches given below.

\section{A. Proposed Optimal Filter Design Approach}

This paper suggests the employment of C-type passive harmonic filter topology for maximization of the hosting capacity, which is expressed as given in Equation (7), under the nonlinear loading conditions.

The constraints of the proposed filter design approach are the PCC voltage rms limits, the individual and total harmonic distortion limits stated in IEEE 519 for the voltage and line current at the PCC, and the current carrying capability limit of the supply line. These six constraints are expressed in Equations (1)-(6). Here it should be mentioned that to increase the energy transfer efficiency of the system; the power factor measured at the PCC should be added as the last constraint into the filter design problem, so that;

$$
0.90 \leq P F=P / S \leq 1.00
$$

where $P$ and $S$ represent the true active and true apparent power demand from the utility:

$$
P=3 \sum_{h} V_{h} I_{h} \cos \theta_{h}, S=3 \sqrt{\sum_{h} V_{h}^{2}} \sqrt{\sum_{h} I_{h}^{2}}
$$

\section{B. Traditional Optimal Filter Design Approaches}

Two well-known objective functions for passive filter design as the THDV minimization and TDDI minimization are considered for the optimal filter design [22]. The constraints of the proposed optimal design approach are also kept for the traditional approaches. Thus, the results of the three filter designs will be evaluated and compared in the next section.

\section{Algorithm for Finding the Optimal Filter Designs}

The algorithm, of which the flow chart is illustrated in Fig. 2, can be employed to calculate the $H C, V_{h}, I_{h}, T H D V, T D D I$, $H D F$ and $P F$ values of the system for the parameter set of the filter designs. Thus, optimal parameter sets of the filter can be found by evaluating these quantities according to the problem formulations of the proposed and traditional design approaches. Here it should be noted that to avoid heavy computational work related to the optimization, Genetic Algorithm (GA) is used to search the optimal filter parameter sets. GA was successfully employed to solve the optimal passive filter design problem in the literature [28]-[30]. In this study, for the solution of the optimization problem, the population size, crossover probability, mutation probability and termination condition parameters of the GA is set as 100 individuals, 0.8, 0.01, and 30 , respectively.

\section{IMPACTS OF THE OPTIMAL FILTER DESIGNS ON THE HOSTING CAPACITY}

The impacts of the optimal filter designs on the hosting capacity is investigated in the studied system, shown in Fig.1. The system has the equipment parameters except the nonlinearity percentage ratio of the nonlinear load same as introduced in section III. In this section, for the analysis, the nonlinearity percentage ratio of the load is set to be $45 \%$. It is 
seen from Fig. 4 that for this nonlinearity percentage value the system's hosting capacity is nil. Additionally, before compensation, THDV and TDDI at the PCC equal $6.2735 \%$ and $13.1736 \%$, for the considered nonlinearity percentage ratio. The measured values of both indices are higher than their limits $(5 \%$ and $8 \%)$ presented in IEEE standard 519.

The filter designs are obtained by considering the proposed approach and the two traditional approaches based THDV and TDDI minimization. The impedance parameters of the obtained filter designs are presented in Table 3 . This table shows that all the three passive filter designs have different $R_{F}$ and $X_{F}$ values. However, this is not the case for $X_{C F 1}$.

The obtained filter designs are individually connected to the PCC. Accordingly, the $H C, V_{r m s}, T H D V, T D D I, H D F$ and $P F$ values are found for each filter design. The results are given in Table 4. It is seen from Table 4 that the $H C$ values provided by the proposed design, THDV minimization and TDDI minimization are $55.34 \%, 38.53 \%$ and $15.60 \%$, respectively. Thus, it is clear that the proposed filter results in considerably higher $H C$ value when compared to traditional ones. In addition to that, the TDDI minimization approach has the lowest $H C$ value for the simulated system case.

On the other hand, all the three filter designs provide very close results for the Vrms, PF, THDV and $H D F$ indices. However, this is not the case for the TDDI index. The TDDI values provided by the proposed design, THDV minimization, and TDDI minimization approaches are 5.55\%,6.22\%, and $4.49 \%$, respectively.

According to the above-summarized results, it should be mentioned that for the studied industrial power system, the proposed design achieves higher hosting capacity level while providing considerably good voltage regulation, power factor improvement, and better harmonic mitigation performance when compared to the traditional filter designs.

TABLE III. THE IMPEDANCE PARAMETERS OF THE OPTIMAL FILTER DESIGNS.

\begin{tabular}{c|c|c|c}
\hline Optimal filter designs & $\boldsymbol{X}_{\boldsymbol{C F} \mathbf{1}}(\mathrm{pu})$ & $\boldsymbol{X}_{\boldsymbol{F}}(\mathrm{pu})$ & $\boldsymbol{R}_{\boldsymbol{F}}(\mathrm{pu})$ \\
\hline $\begin{array}{c}\text { The proposed design } \\
\begin{array}{c}\text { THDV minimization based } \\
\text { design }\end{array}\end{array}$ & 0.2367 & 0.0629 & 0.9297 \\
\hline $\begin{array}{c}\text { TDDI minimization based } \\
\text { design }\end{array}$ & 0.2372 & 0.0655 & 2.8752 \\
\hline
\end{tabular}

TABLE IV. THE OBTAINED $H C, V R M S, T H D V, T D D I, H D F, P F$ VALUES FOR EACH FILTER DESIGN.

\begin{tabular}{c|c|c|c}
\hline & $\begin{array}{c}\text { Proposed } \\
\text { design }\end{array}$ & $\begin{array}{c}\text { THDV } \\
\text { minimization } \\
\text { based design }\end{array}$ & $\begin{array}{c}\text { TDDI } \\
\text { minimization } \\
\text { based design }\end{array}$ \\
\hline$H C(\%)$ & 55.34 & 38.53 & 15.60 \\
\hline$V_{r m s}(\mathrm{pu})$ & 0.97 & 0.97 & 0.97 \\
\hline$T H D V(\%)$ & 2.69 & 2.66 & 2.96 \\
\hline$T D D I(\%)$ & 5.55 & 6.22 & 4.49 \\
\hline$P F(\%)$ & 99.74 & 99.68 & 99.80 \\
\hline$H D F(\%)$ & 99.57 & 99.49 & 99.65 \\
\hline
\end{tabular}

\section{CONCLUSION}

In this paper, firstly, the PV-based DG hosting (or maximum allowable) capacity of a typical two-bus industrial distribution system is evaluated for various nonlinearity levels of the load side. For the evaluation, the hosting capacity is determined by considering the harmonic constraints, total and individual harmonic distortion limits stated in IEEE Standard 519, and the conventional hosting capacity constraints, bus rms voltage limit and the current carrying capability limit of the supply cables. The results show that the hosting capacity of the studied PV-DG unit dramatically decreases with the increment of the nonlinearity percentage ratio of the load side.

Thus, in the second part of the study, a C-type filter is employed to maximize the hosting capacity while satisfying the IEEE standard 519 voltage and current harmonic distortion limits, bus rms voltage and the line's current carrying capability limit, and providing the desired power factor. For the distorted distribution system under study, the proposed and the traditional passive filter design approaches are evaluated by regarding their impact on the hosting capacity. For the studied system, the results indicate that the proposed filter design achieves higher hosting capacity level while providing considerably good voltage regulation, power factor improvement, and enhanced harmonic mitigation capability when compared to the traditional filter designs.

\section{REFERENCES}

[1] N. Jenkins, R. Allan, P. Crossley, D. Kirschen, G. Strbac, "Embedded Generation", IET Power and Energy Series 31, reprinted 2008.

[2] P. Paliwal, N.P. Patidar, R.K. Nema, "Planning of grid integrated distributed generators: a review of technology, objectives and techniques," Renewable and Sustainable Energy Reviews, vol. 40, pp. 557-570, Dec. 2014

[3] T. Ackermann, G. Anderson, L. Söder, "Distributed generation: a definition," Electric Power Systems Research, vol. 57, no. 3, pp. 195204, Apr. 2001.

[4] R. A. Walling, R. Saint, R. C. Dugan, J. Burke, L. A. Kojovic, "Summary of distributed resources impact on power delivery systems", IEEE Trans. on Power Delivery, vol. 23, no. 3, pp. 1636-1644, Jul. 2008.

[5] F. H. Guan, D. M. Zhao, X. Zhang, B. T. Shan, Z. Liu, "Research on distributed generation technologies and its impacts on power system", Int. Conf. on Sustainable Power Generation and Supply, pp. 1-6, Nanjing, 6-7 April 2009.

[6] R. Viral, D. K. Khatod, "Optimal planning of distributed generation systems in distribution system: a review", Renewable and Sustainable Energy Reviews, vol. 16, no.7, pp. 5146-5165, Sep. 2012.

[7] P. Prakash, K. Khatod, "Optimal sizing and siting techniques for distributed generation in distribution systems: a review", Renewable and Sustainable Energy Reviews, vol. 57, pp. 111-130, May 2016.

[8] V. E. Wanger et al., "Effects of harmonics on equipment", IEEE Trans. on Power Delivery, vol. 8, no. 2, pp. 672-680, Apr. 1993.

[9] M. E. Balci, A. E. Emanuel, "Apparent power definitions: a comparison study”, Int. Review Elec. Engineering, vol. 6, no. 6, pp. 2713-2722, Nov. 2011.

[10] M. E. Balci, M. H. Hocaoglu, "Effects of source voltage harmonics on power factor compensation in ac chopper circuits", Electrical Power Quality and Utilisation Journal, vol. 14, no. 1, pp. 53-60, Sept. 2008.

[11] IEEE Recommended Practices and Requirements for Harmonic Control in Electrical Power Systems, IEEE 519, 2014.

[12] A. Bhowmik, A. Maitra, S. M. Halpin, J. E. Schatz, "Determination of allowable penetration levels of distributed generation resources based on 
harmonic limit considerations", IEEE Trans. on Power Delivery, vol. 18, no. 2, pp. 619- 624, Apr. 2003.

[13] V. R. Pandi, H. H. Zeineldin, W. Xiao, "Allowable DG penetration level considering harmonic distortions", 37th Annual Conf. on IEEE Industrial Electronics Society, pp. 814-818, Melbourne, VIC, Nov. 2011.

[14] K. Dartawan, R. Austria, L. Hui, M. Suehiro, "Harmonic issues that limit solar photovoltaic generation on distribution circuits", Solar 2012, pp. 1-7, Colorado, 13-17 May 2012.

[15] W. Sun, G. P. Harrison, S. Z. Djokic, "Distribution network capacity assessment: incorporating harmonic distortion limits", 2012 IEEE Power and Energy Society General Meeting, pp. 1-7, San Diego, CA, 22-26 Jul. 2012.

[16] V. R. Pandi, H. H. Zeineldin, W. Xiao, A. F. Zobaa, "Optimal penetration levels for inverter- based distributed generation considering harmonic limits", Electric Power Systems Research, vol. 97, pp. 68-75, Apr. 2013.

[17] I. N. Santos, V. Cuk, P. M. Almeida, M. H. J. Bollen, P. F. Ribeiro, "Considerations on hosting capacity for harmonic distortions on transmission and distribution systems", Electric Power Systems Research, vol. 119, pp. 199- 206, Feb. 2015.

[18] M. Mohammadi, A. Rozbahani, M. Montazeri, "Multi criteria simultaneous planning of passive filters and distributed generation simultaneously in distribution system considering nonlinear loads with adaptive bacterial foraging optimization approach", Int. Journal of Electrical Power \& Energy Systems, vol.79, pp. 253- 262, Jul. 2016.

[19] N. Ghaffarzadeh, H. Sadeghi, "A new efficient BBO based method for simultaneous placement of inverter-based DG units and capacitors considering harmonic limits", Int. Journal of Electrical Power \& Energy Systems, vol. 80, pp. 37-45, Sept. 2016.

[20] S. H. E. Abdel Aleem, A. F. Zobaa, M. M. Abdel Aziz, "Optimal C-type passive filter based on minimization of the voltage harmonic distortion for nonlinear loads", IEEE Trans. on Industrial Electronics, vol. 59, no. 1, pp. 281-289, Jan. 2012.
[21] M. E. Balci, A. D. Karaoglan, "Optimal design of C-type passive filters based on response surface methodology for typical industrial power systems", Electric Power Components and Systems, vol. 41, no. 7, pp. 653-668, Apr. 2013.

[22] M. E. Balci, "Optimal C-type filter design to maximize transformer's loading capability under non-sinusoidal conditions", Electric Power Components and Systems, vol. 42, no. 14, pp. 1565-1575, Sept. 2014.

[23] S. Sakar, M. E. Balci, "Optimal design of single-tuned passive filters to minimize harmonic loss factor", Middle East Journal of Scientific Research, vol. 21, no. 11, pp. 2149-2155, Nov. 2014.

[24] S. H. E. Abdel Aleem, M. E. Balci, S. Sakar, "Effective utilization of cables and transformers using passive filters for non-linear loads", Int. Journal of Electrical Power \& Energy Systems, vol. 71, pp. 344-350, Oct. 2015.

[25] J. D. Glover, M. S. Sarma, T. J. Overbye, G. X. Luo, "Power System Analysis\&Design",. Cengage Learning; 5th edition, 2011.

[26] A. R. Olive, J. C. Balda, "A PV dispersed generator: a power quality analysis within the IEEE 519", IEEE Trans. on Power Delivery, vol. 18 , no. 2, pp. 525- 530, Apr. 2003.

[27] IEEE P1547, "Standard for Distributed Resources Interconnected With Electric Power Systems", 2002.

[28] P. Zacharia, A. Menti, T. Zacharias, "Genetic algorithm-based optimal design of shunt compensators in the presence of harmonics", Electric Power Systems Research, vol. 78, no. 4, pp. 728-735, Apr. 2008.

[29] I. F. Mohamed, S. H. E. Abdel Aleem, A. M. Ibrahim, and A. F. Zobaa, "Optimal sizing of C-Type passive filters under non-sinusoidal conditions", Energy Technology \& Policy, vol. 1, no. 1, pp. 35-44, 2014.

[30] S. H. E. Abdel Aleem, A. M. Ibrahim, and A. F. Zobaa, "Harmonic assessment-based adjusted current total harmonic distortion", The Journal of Engineering, 2016. DOI: 10.1049/joe.2016.0002 